ADVERSARY MODELING: AN ANALYSIS OF CRIMINAL ACTIVI'TIES

ANALOCOUS TO POTENTIAI, THREATS TO NUCLEAR SAFEGUARD SYSTEMS

Prepared by

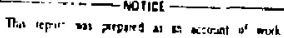

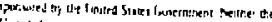

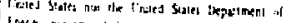

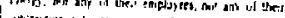

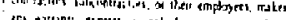

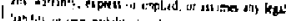

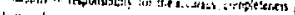

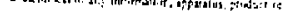

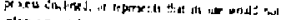

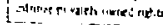

J. M. Heineke and Associates

under purchase order $\# 2426009$

For the University of California,

Lawrence Livermore Laboratory

December 20, 1978 
I. Introduction 1

II. The Internal Threat (Bank Frauds and Embezzlenents) 4

A. Law Enforcenent and Industry fvaluation of the 5 Internal Threat: An Overview

B. Analysis of the Insider Threat: Summary iatistics 8

C. The Conspiracy Problem 11

D. The Size of Losses and Anounts Recuvered: inther 15 Analys is

E. The Distribution of kank Frand and Eimbezzlement losses 22 and the Relitive frequency of Occurrence

i) The Redative frequency of occurrence 22

ii) The Distribution of loss Size $\quad .6$

III. The External Threat (Aircraft Hijackings and llustage-Type 28 Torrotict mintes)

A. Mirctaft Hijacking 28

B. Rrububi]ity of an Nirctaft ll jacking 38

C. T'rrorist kvents with Hostages 40

IV. Suminary $\quad 45$

V. Appendix: Data Sets Utilized 49 


\section{LIST OF TABLLES}

$\underline{\text { Table }}$

Page

1 Relative Importance of Various External and Internal Threats to Commercial Banks

2 Mean Losses by Position of Perpetrator

3 Period Concealed by Position of Perpetrator

4 Mean Per Cent Recovered by Position of Perpetrator

5 Collusion Anong Insiders: The Distribution of Group Size

6 Collusion by Pasition

7 Collusion and Mean losses

8 Periad Concealed and Collusion

9 Predicted Losses by Managerial Kank, Collusion and Bank Size 19

10 Predicted Recoveries by Bank Size and Concealment Period

11 Predicted Frequencies of Bank Fraud and tmbezzlements (per year):25 Several Cases

12 Aircraft lijackings 1961-77: Number of Perpetrators 31

13 Eìusticities of $\mathrm{H}$ (at sample means) 33

14 Predicted Hijackings: Selected Cases 34

15 The Relative Importance of Screening vs. Changes in $P_{a}, P_{c} \quad 37$ and $M_{S}$ in Deterring Hijackers

16 Distribution of Group Size for "Hostage-Type" Terrorist Events 41

17 Predicted Hostage-Type Terrorist Ryents per Quarter: Selected 44 Cases 


\section{INTRODUCTION}

In this study we have examined and subjected to analysis several classes of incidents in which decision makers are confronted with adversaries. Classes of incidents were selected such that one or more attributes of ti:e chosen incidents are analagous to attributes of potential siluations in which an adversary interacts with a material control system in a nuclear facility.

The first portion of our study focuses upon the threat posed internally, i.e. upon the threat posed by employces and management to the security of the institution. The analog situation we have ehosen for our analysis of the internal threat is bank fraud and embezzleinent cassa in U.S. commercial banks. Our data set consists of detailed information on 880 individual cases. In each of these cases trusted employees at all levels, working either alone or in collusion with others, have diverted firm assets for their orl financial gain. We liwe ussd these data to gauge the severity of the internal thruat reditive lu extermal throats (prinibily bank robbery); to asrertain the relative importance of insider collusion in divertine assets; to study the role an employee's or manager's position plays in bank fraud and embrezlement cases; and to estinace equations relating the size of losses and amounts recovered to a number of factors which are co-determinants of these variables. Equations are also estinated linking the distribution of loss size and the frequency of losser to variables measuring the "quality" of regulatory controls, relative wages in the banking industry and the size of the bank. Throughout, measures of sensitivity of dependent variables to changes In various internal and external controls are calculated.

In the seconic portion of the study, we inalyze certain aspects of the external

threat to the security of nuclear. facilities again from the perspective of analog situations. liere we have utflized information on aircraft hijackings and on terrorist events in which hostages were taken in an attempt to extract demands. Data on 
190 alrcraft hijackings have been used to study the effect on the Erequency of these cvents of changes in levels of enforcement and changes in the severity of punishment if a hijacker is arrested and cunvicted, among other variables. The basic question here, which transcends aircraft hijackings, is whether one can provide hard evidence that increased enforcencut and sanction lovels lead to Increased levels of deterrence. We have also used these data to assess the effectiveness of physical screening devices relative to increased eniorcement and sanction levels. 'The number of aircraft hijackings per quarter are predicted under several policy scenarios.

The final pages of the report contain the results of a preliminary analysis of terrorlst events in which hostages were taken in an attempt to eztract either financial, prisoner release or political demands. A sample of 249 incidents was drawn from the ITERATE data tape prepared for the office of Political Rescarch at CIA and the Rand publication International Terrorism: A Clironology. Attention is focused primarily upon analyzing, the impartance of the frequency of past tererorist events in determining the level of "current" terrorist activity and on evaluating the role of media covereage of terrorist events in the "recent" past in deturmining the "current" level of these events. In other words, would an extris n column inches devoted to a lerrorist attack in a major newspaper lead to a higher predicted number of similar attacks in some subsequent period. Many political scientists have claimed this to be the case. The report is concluded with a summiry of our findings and an appendix which contains a detailed description of the data scts we have utilized in our analysis. These data sets have been turned over to LIL to permit further analysis if such is deemed appropriate.

A few words on the nature of the similarity between the events we have studied and possible threats to nuclear facilities is probably in order at this time. First, the case of bank frauds and embezzlements. Comnercial banks in the United States 
are viewed as among the most secure of private sector institutions. Bank of ficials are known to be cautious, risk averse managers whose manugerial conservatisin is reinforced by highly sophisticated internal controls and accounting systems. Yet in recent years there have been over 10,000 cases a year in which trusted "insiders" divert bank assets to their own uses. Losses from the se insider frauds and embezalements is close to a third of a million dollars a year. And the data indicate that far the greatest threat is posed by top management and presidents--porsons who in general are pillars of their communities and in point of fact, would easily pass the most stringent of security checks. To the extent that black markets exists for SNM, the analogy between bank inanagenent and nucluar facility munagement is quite close. But we will see below that the andogy is consideribly broader than one based on financial motivations alone.

The airline industry provides a particularly goud example of a seeningly secure institution which rather suddenly became the target of a severe thrcat--aircraft hijacking. The response of the industry and its resulators to the theat presents an excellent opportunity to analyze the response of adversaries to policy changes specifically designerl to minimize the adversary threat.

Fina11y, the analogy between "hostage-type" terrorist events in society at large and "hostage-type" terrorist rvents directed at nuclear facilities is of course immediate. Cases where hostages are taken and threatened with death unless certain demands are met, surely must rank among the most severe of external threats to nuclear facilities. 
THE INTERNAT THREAl' ( Bank Frauds and Embezzlements)

We have utilized rather extensive data on embezzlements Erom U.S. Einancial institutions in our attempt. to place the internal threat into perspective. In particular, our data consist of 880 bank fraud and embezlement cases reported to the Federal Deposit Insurance Corporation (FDIC) over the years 1973-1977. These are the total number of reported bank fraud and embezmlement cases over $\$ 10,000$ in this period for institutions regulated by FDIC. To get a fecling for the overall scope of the bank fraud-embezlement problem, it should be kep: in mind that losses of $\$ 10,000$ and larger represent only approximately $9 \%$ of the totid number of losses but approximately $52 \%$ of the total dollat loss. In addition, FUIC is but one of three agencies concerned with regulating the nation's banks. The other two are the Comptroller of the Currency which is responsible for national banks and the Federal Reserve which is responsible for state chartered banks which belong to the Federal Reserve system. FDIC is responsible For non-lideral Reserve, state chartered banks.

As far as numbers of banks are concerned, FDIC is respunsible for the gruatest number of institutions--approximately 8,341 , in 1973 where our sample bagins, with the Federal Reserve being responsible for approximately 1,076 banks and the Comptroller of the Currency responsible for 4661 banks. But in telns of deposits, in 1973, the Comptroller's office was primarily responsible for banks with $56 \%$ of total U.S, banking deposits with the Federal Reserve and Fl)IC having primary responsibility for banks with $19 \%$ and $25 \%$ of total deposits, respectively. Ceteris paribis, this implies there were roughly 3600 bank fraud and embezalement incidents over $\$ 10,000$ in the 1973-77 period and roughly 40,500 bank fraud and embezzlements ( $B$ F \& E) of al1 sizes. B F \& E losses over $\$ 10,000$ at FDIC regulated banks in this period were $\$ 142.49$ million. Using the $52 \%$ figure noied above, total losses at FDIC regulated banks were, ceteris paribis, approximately $\$ 274.02$ million and total U.S. losses over all regulated banks were roughly $\$ 1.14$ billion or roughly $\$ 228$ million per yeur. 
Law Enforcement and Industry Evaluation of the Internal Threat: An Overview

In this section we set the stage for the quantitative evidence to be detailed later in our report. 'lo begin we summarize banking industry soulces and FBI statistics concerning the threat from "trusted employees and of ficials".

"The odds are against you on embezzlement... the analysis of the Federal Bureau of Investigation indicates that well over 10,000 bank fraud and embezzlement cases are anticipated this year (1978)...noreover, the FlBI dala are based on cases that the agency receives from banks--and there is a diffurence between that figure and the actual experience of banks. A significant number of cubezzlements should be reported but are not for hunanistic or other reasons." So states the author of an article in Bank Security Report*. Fraud and embezzlement are part of the risk of banking. The point is that they are more prevalent in institutions which do not have effective audit programs and in those banks that view their officers as not being subject to temptation. The FBI claims that a very important start for controlling embezzlement is for top manigenent to have a strong committment, known to employecs, to internal control.

FBI and indust:ry trade groups recommend that bank maniggenent answer the following questions: Does every officer and employee take at leust a two (consecutive) week vacation? Are officers or enployees on vacation allowed to visit the bank to "pick up mail" or "help out" in his or her department? Are officers and staff rotated without notice? It seems that few banks practice $100 \%$ rotation. Tellers and bookkeepers are periodically moved around, but individuals in "the official family" are not. Yet our data and auxillary FBI data indicate that it is officers of banks that are more likely to be engaged in fraud and embezzlement.

* Dank Security Reports, volume 7, number 8, August 1978. 
In a 1975 article published in a banking trade association journal* Clarence Kelly, ex-director of the FBI, discussed internal and external attacks on banks. He noted that from the standpoint of financial losses and investigative time required, internal attacks on banking institutions--bank fraud and emberalements--are much the more serious problem. In the past decade "...these problems have been occurring with ever increasing erequency and with greater degrees of sophistication." FBI Annual Reports indicate investigations of violations 1 al.al ed 3092 cases in FY 1968, increased to 4941 casias in l'Y 1971, increased to 7820 cases in FY 1974 and is expected to be approximately 10,000 cases in FY 1978--a growth rate in the neighborhood of twenty per cent a year. And as Mr. Kelley has pointed out "... the perpetrator of the internal attacks is most often a trusted bank officcs. l'u uncover this kind of theft requires, in nost cases, considerable time and expense."

A second problem in the banking industry that has serious implications for the nuclear industry is the increasing incidence of extortionate demands against banks. These crimes involve the taking of hostages and/or threats of violence and is a violation of a federal statute known as the Hobbs Act. In a typical hobbs $\mathrm{Act}$ case a bank executive reccives a phone call at the bank advising him that his wife or some other family member is being held hostage. He is told that unless he produces a certain amount of money at a given time and location, his loved one will be killed.

Summary information on Hobbs Act cases and bank fraul and embezzlement cases is presented in Table I. The information was derived from semi-annual reports prepared by the white Collar Crime unit at the FBI. The reports were begun in 1973 . In the table wo have also included information on the traditional external threats to banks ...bank robbery, burglary and larceny $(R, B \& L)$. We see that the inturial thrcat(BF \& $E)$ 
Relative Itportance or V3rious Externil an! luternal thrants to Co:mercial Banksis

TALL: 1 .

\begin{tabular}{|c|c|c|c|c|c|c|c|}
\hline & Period & $\begin{array}{l}\mathrm{R}, \mathrm{F} \& \mathrm{I} \\
\text { Cases }\end{array}$ & $\begin{array}{l}\text { boibs det } \\
\text { Cilses }\end{array}$ & $\begin{array}{l}P \mathrm{~F} \leq \mathrm{H} \\
\text { Cascis }\end{array}$ & $\frac{\mathrm{B}}{\mathrm{R}, \mathrm{B}}, \frac{\mathrm{E}}{\mathrm{B}} \mathrm{l}$ losses & $\frac{\mathrm{B}}{\mathrm{R}, \mathrm{F} \& \mathrm{E} \text { cases }}$ & $\frac{R, B}{\text { Hobbs }} \frac{L \text { cases }}{A c t} \frac{{ }^{2} \text { cases }}{}$ \\
\hline $7 / 73$ & $-12 / 73$ & 1681 & $12 \mathrm{f}$ & 3905 & 6.52 & 2.37 & 13.35 \\
\hline $1 / 74$ & $-6 / 74$ & 1804 & 148 & $38: 5$ & 4.83 & 2.12 & 12.20 \\
\hline $7 / 74$ & $-12 / 74$ & 2449 & 194 & 5931 & 4.19 & 2.42 & 12.63 \\
\hline $1 / 75$ & $-6 / 75$ & $26 \square 1$ & 179 & $\therefore 250$ & 4.32 & 1.63 & 14.53 \\
\hline $7 / 75$ & $-12 / 75$ & 2354 & 150 & $70: 1$ & 7.83 & 2.99 & 15.70 \\
\hline $1 / 76$ & $-6 / 76$ & 2157 & $13 r$ & $40: 1$ & 7.25 & 1.50 & 15.87 \\
\hline $7 / 76$ & $-12 / 76$ & $2 \div 08$ & 101 & 4727 & $x$ & 1.96 & 23.87 \\
\hline $1 / 77$ & $-6 / 77$ & 2297 & $9 \div$ & $4 \therefore 3$ & $\therefore$ & 1.92 & 2.3 .47 \\
\hline
\end{tabular}

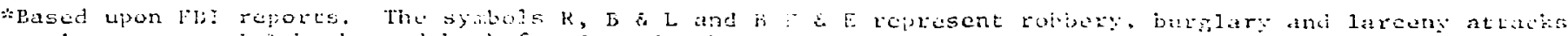

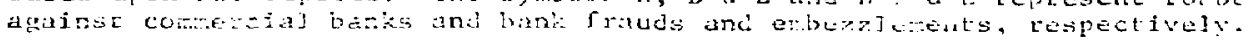


measured in terms of the number of cases, averages about twice as severe as the traditional external threat of $R, B \& L$. If we measure the threat in terms of the size of the loss sustained, then $B F \& E$ poses a four to eight times larger threat than robberies, burglaries and larcenics with losses averaging about six times larger for the internal threat. The other external lilreat to banks is liobbs Act cases. Although there is on average only one of these cases for each 15 rokbery, burglary or larceny case, the threat posed by this tactic for the nuclear industry is clear.

As one begins to grasp the extent of the insider threat in financial institutions, it is well to keep in mind that bank managenent is among the more cautious, conservative and risk averae of private suctor managers and that banking institutions with their increasingly sophisticated accounting systems are vicwed as among the most secure of institutions. Nonetheless, in a recent independent survey of 1932 B F \& E cases over the years 1968-70 the Bank Administraltiun Institute (B.A.I.) found (i) dollar losses increased in wach of the three years; (ii) a likely trend toward increased periods of concealment; (iii) a year to year increase in the use of sophisticated irregular accounting entries to accomplish embezzlcments, (In fact, of the 1932 cases reported in the B.A.I. sample over one thitd were committed witl pen and pencil through the use of fictious or forged entrics and irregular accounting entries) and inally, (iv) that increasingly, persons of high managerial rank are involved in bank fraud and embezzlement. We present much more information on each of these points based upon our own sample of FDIC cases in what iallows. Analysis of the Insider Threat: Sumary Statistics

One question of considerable interest to both manugement and regulators of financial institutions concerns which employee and managerial ranks tend to present the more severc threats to the integrity of the iustitution. To get a handle on 
this question we partitioned our sample by position. Hore precisely, we defined four mutually exclusive and exhaustive generic positions:

Position 1: Executive (President or Director)

Position 2: Top Managemnt (Cashiers, Sunior Vice Presidents, Operations Officers, Trust Officers, Treasurers)

Position 3: Low-Middle "anagement (Assistant Cashier:, Vice Presidents, Branch Managers, Head tellers, etc, )

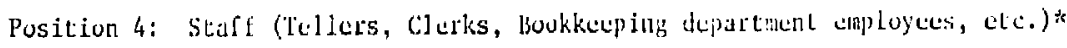

In our sample of 880 cases, $31.6 \%$ of all cascs invulved l'residents and/or Directors; $10.8 \%$ involved top management; $44.0 \%$ irvolved Jow-middle nilnegenent and $13.5 \%$ invalved employee level personnel. One expects to find a large proportion of all losses coming from the ranks of low-middle manilgement, due both to relatively low level of background screening done for entry level management positions and the relatively low remuneration received by these indjvijuals. (We will have inure to say below on the role relative wages play in the emberzlement equation.) What is somewhat surprising is that almost one thitd of ail serious losies (lusses greater than $\$ 10,000)$ are perpetrated by bank presidents or directors. These individuals typically have impeccable credentials, have been in the industry most of their lives and in point of fact would easily pass the most severe and detailed sccurity check available.

To continue our analysis of losses by position, we nexl: calculated the average size of the loss by position of the perpetrator. These findings are summarized in Table 2

\begin{tabular}{|l|c|}
\hline Table $2-$ Mean Losses by Position of Peratialur \\
\hline Position & Mean Loss iper case) \\
\hline President or Director & $\$ 244,100$ \\
Top Management & $\$ 137,559$ \\
Middle Management & $\$ 156,866$ \\
Staff & $\$ 90,045$ \\
\hline
\end{tabular}

* Data on the total number of individuals in each of these calegories is not available. 
In interpreting Table 2 keep in mind that the only losses in our sample are those over $\$ 10_{1} 000$. If smaller losses were also included, one would find a substantial reduction in the mean size of the loss in the lower ranks and little or no reduction in the figure we have repor'sd for top executives, since ther seem to be very few losses under $\$ 10,000$ traceable to presidents and directors.

In Table 3, we have presented a breakdown on the length of time individuals are able to keep BF \& E activilies soncealed cross tabulated with the position of the perpetrator.

\begin{tabular}{|l|c|}
\hline Table 3--Period Concealed by Position of Perpetritor \\
\hline Position & Mean Period Concealed(months) \\
\hline President or Director & 19.24 \\
Top Management & 19.84 \\
Middle Management & 20.85 \\
Staff & 7.86 \\
\hline
\end{tabular}

Our data indicate there are but insignificant differences in the period of time managers of all levels and presidents are able to conceal their activities. The mean time concealed in each position is approximately one and two thirds years. But for: individuals at the very bottom of the position structure, the mean time activities were concealed is approximately a year less than for "higher ups". of course, on the one hand, these findings are what one would expect as managers should have much more opportunity to conceal thcir activitias than mere clerks and tellers. In addition, the level of trust is higher as one moves up the ranks. Tellers and clerks are strictly controlled and carefully watched, often on a day by day basis. This becomes increasingly less the case as one proceeds up through the various levels of management. On the other hand, 
Table 3 presents the unexpected finding that presidents who, as a rule, possess both the highest degree of autonomy and are the most trusted of all insiders are able to conccal their activities no longer than other ranks of management. The explanation for this anamoly may stem from the fact that losses traccuble to presidents are considerably larger on average and large losses are easier to uncover or from the fact that because president are pretty much exempt from internal controls leads state and federal examiners to pay special attertion to these individuals.

In Table 4, we present the ratio of the mean anounts recuvered to the mean size of the loss (percent recovered). Again, calculations are done for each position.

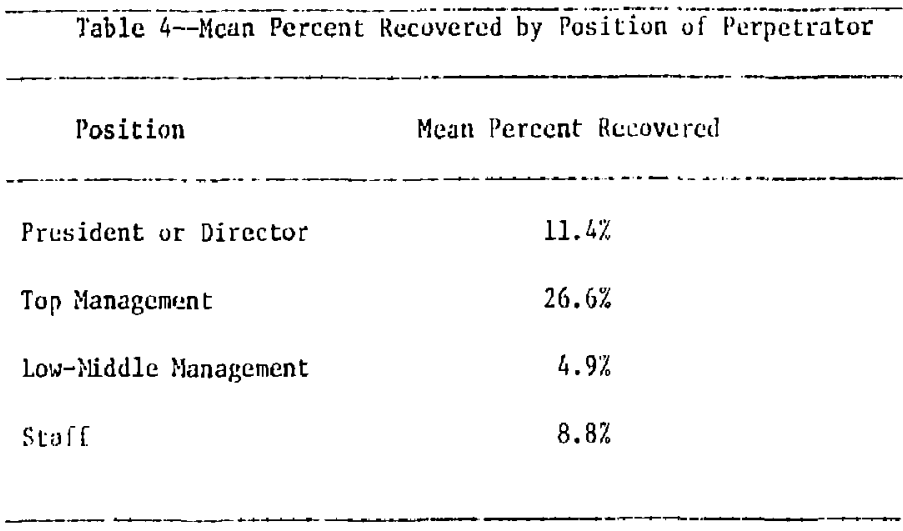

\section{The Conspiracy Probicm}

In this suction we present some of urr findings concerning the role of conspiracies among insiders--conspiracies formed to facilitate the bank fraud and embezzlement process. First, of the 880 B F \& E cases in the FIIC data set, 201 irvolve insider conspiracy. That is, $22.8 \%$ of all large losses involved collusion among insiders. In Table 5 we break these 201 cases down by the number of insiders involved in each conspiracy. 


\begin{tabular}{|c|c|}
\hline Nat.1e 5-Collusion Among Insidars: The Distribution of Group Size \\
\hline Number in Group & Number of Cases \\
\hline 2 & 230 \\
3 & 43 \\
4 & 15 \\
5 & 5 \\
$6-10$ & 6 \\
$11-15$ & 1 \\
$15-20$ & 1 \\
\hline
\end{tabular}

The largest two conspiracies in the sample Involved a bank in California in which the president and fifteen employees emberzled $\$ 550,000$ and a bank in Missouri in which twelve members of the board of directors and two bank of ficers embezzled $\$ 100,000$.

It is interesting to note that Bank Auministration Institute's study of 1932 cases, referenced above, for the years 1968-70 found that only six percent of all cases involved insider collusion. But prophetically enough, the authors then stated that ..."Nevertheless, in each of the three years the incidence of collusion increased and is worthy of further analysis." As we have reported, by the line of our sample, 1973-1977, the percent of cases involving collusion had risen from $6 \%$ to roughly $23 \%$ of all bank fraud and embezzlement cases. The report then notes that ..."Frauds involving collusion are always very difficult for the bank auditor. They have a tendency to become complex, are more difficult to uncover, become large in amount, and have longer periods of concealment." We will provide more information on the latter two points shortly.

In Table 6, we have cross tabulated collusion cases with the position of the highest ranking consplrator in the group. Bank presidents and directors are involved in alnost $60 \%$ of all conspiracies to defraud banks! of course, top management may also be involved in these cases, but the salient point would seem to be that the instigator almost certainly would have been the higher ranking official. 


\begin{tabular}{|l|c|}
\hline \multicolumn{2}{|c|}{ Table 6--Collusion by Position } \\
\hline Position & Percentage of T'otal Cases \\
\hline President or Director & $57.2 \%$ \\
Trp Management & $8.5 \%$ \\
Low-Middle Management & $25.9 \%$ \\
Staff & $8.5 \%$ \\
\hline
\end{tabular}

The other breeding ground for conspiracies is in the group of low-middle managers. But the incidence here is less than half that at the rank of president and director. There seens to be a much smaller threat that conspiracies will originate in the ranks of top management or among staf $f$ level personucl. In the latter case, the reason is no doubt largely the lack of opportunity. The Bank Administration Institute study we have been quoting offers the following observalion on this point: "lrauds by officers generally are larger and concealed lomper because the officer's position permits him to override controls more readily than others in the bank. Very few persons ather than bank auditors will question the actions of bank officers. Whenever an officer becomes involved in a fraud, the method used generally will be fictitious and Eurged entries or irregular accounting entries rather than theft or withholding..." The B.A.I. study concluded that frauds involving collusion posed a special risk for a number of reasons, among which are longer periods of concealment and larger amounts stalen. In Tables 7 and 8, we sunmarize our data on these two points.

\begin{tabular}{|c|c|c|}
\hline \multicolumn{2}{|c|}{ Table 7 -- Collusion and Mean Losses } \\
\hline \multirow{3}{*}{ Mean Size of Loss } & Collusion & No Collusion \\
\cline { 2 - 3 } & $\$ 250,416$ & $\$ 135,724$ \\
\hline
\end{tabular}




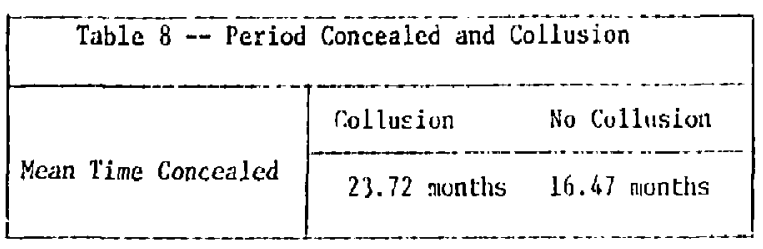

We find that mean losses tend to be $84 \%$ liarger in castes involving collusiun and the average time the fratul or embezzlement is concealed is $44 \%$ lunger when collusion is involved. Since these two quantities, amounts stulen and tiate until detection, are of primary importance in designing a miaterials cuntrol system, the evidence that conspiracy exacerbates the control problem should cause serious attention to be directed to control systems Jesigned to thinimize the collusion problem.

Before golng on to present the results of a stirly we undertuok to explain more fully the determinants of the size of the loss and the amount recovered, we point out a recent practice in banking that may have sume bearing on the material control problem. As the fraud and embezzlenent problem in banking has grown over the years, insurance deductibles have grown causing many banks to establish an expense reserve account for losses. Charges are accrued monthly and the reserve fund takes care of losses when they occur. This action evens out any monthly fluctuations on the income statement due to fraud losses. Of course, this is perfectly legitimate tactic for bank managers to pursue, but the analog is obviously hiighly undesirable to regulators charged with munitoring nuclear materials. Like bank managers with reserve accounts, plant managers have strong incentives to stockpile SM to be used as a "reserve account" to take care of missing materials (MUF's). Of course, suck stockpiling of SMM would be strictly prohibited, so the "account" could be effectively established only by a manager diverting very small amounts of SMM, on say, a continuous basis. 
The point here is that the incentive structure facing management in banks and management in nuclear facilities is virtually identical. In the former case the action leads to a legitimate, though perhaps undesirable, conclusion--the establishment of reserve accounts to cover expected losses. (The action is undesirable to the extent that it causes management to be less vigilant in protecting the banks assets.) In the latter case, the analogous action abrogates the whole notion of a secure materials accounting system and under many scenarios may lead to most undesirable consequences. One final point: Intelligence sources in the banking industry are confident that the vast majority of $B F \&$ : cases are detected, eventually. After all, even the most sophisticated accounting schene will be uncovered when the perpetrator retires, takes another posiri on or dies if the funds have not been replaced--unless, of course, there has been collusion and the remaining menbers carry on as other members leave the bank. This would seen too difficult to accomplish in most realistic scenarios.

The Size of Losses and Anounts Recovered: Further Analys is

In an effort to explain more fully the factors responsible for the size of losses and the amounts recovered we have used multiple regression andysis to further investigate the role of the position of perpetrators and other factors in determining these quantities. The data used in the analysis are again the 680 B F \& E cases reported to EDIC in the period 1973-1977. The estimaled equations and relevant test statistics are listed next and then disçussed.

$$
\begin{aligned}
& \text { Size }=-192.39+22: .35 \mathrm{P}_{1}+156.16 \mathrm{P}_{2}+137.29 \mathrm{P}_{3}+91.60 \mathrm{C}+16.06 \mathrm{ABA} \\
& \begin{array}{lllll}
(67.25) \quad(55.56) \quad(63.64) \quad(47.65) \quad(38.52) \quad(4.01)
\end{array} \\
& F(5,804)=7.29 \\
& \text { Rec }=8.19+11.16 \mathrm{P}_{1}+7.33 \mathrm{P}_{2}+5.58 \mathrm{P}_{3}-.340 \mathrm{ABA}-.122 \mathrm{Cen} \\
& \begin{array}{lllll}
(5.18) & (4.08) \quad(4.90) \quad(3.68) \quad(.295) \quad(.063)
\end{array} \\
& F(5,414)=3.67
\end{aligned}
$$


The variables entering these cquations and their units of measurement are:

Size $=$ size of loss (thousands of dollars)

$P_{1}=1$ If perpetrator was president or director, and $P_{1}=0$ otherwise

$P_{2}=1$ if perpetrator was top management, and $P_{2}=0$ otherwise

$P_{3}=1$ if perpetrator was low-middle management and $P_{3}=0$ otherwise

$C=1$ If collusion is involved, 0 otherwise

Con $=$ period of time fraud or enbezalement was conicaled (montis)

Rec $=$ amount recovered (thousands of dollars)

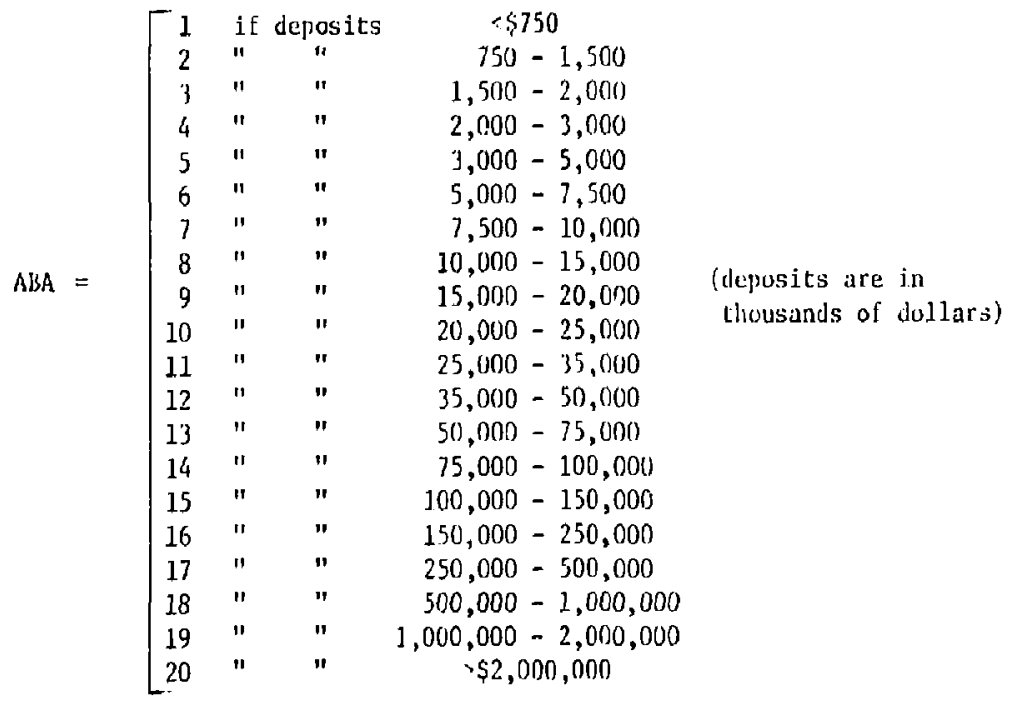

The variable $A B A$ represents the American Banking Association's measure of bank size as given by total deposits. The notation $F(a, b)$ represents the value of the F statistic with "a" degrees of freedom in the numeratur and " $b$ " in the denominator. The substantially lower number of degrees of frcedom th the second regression equation arises primarily from sketchy data on period concealed (Con) whick is unknown in almost half the total cases. Standard errors associated with each of the estimated coefficients are given under the coefficient in parenthesis. 
of course the influences on the size of losses and amounts recovered are many and our variables represent but a few of the major influences. If the myriad of influences on Size and Rec which have becn omitted from our equations are anproximately normally distributed, then classical statistical tests may be used to evaluate our estimates. To the extent that these omitted factors have, individualiy, but a small influence on Size and Rec and alise from numerous different sources, then it is appropriate to call upon the central limit Theorem and to postulate that the sum of all onitted factors in these equations is normally distributed. We adopt this hypothesis througlout vur report. In this case " $t$ " and "F" tests may be used to evaluate individual parancter estimates and the overall significance of estimated equations, respcctively. In more detail, "t" tests will be used to test the hypothesis that a given independent variablu has a nonzero effect on the dependent variable (i.c., wiether a given parameter estimate is significantly different from zero); while the "l:" Lest will be used to test the hypothesis that the set of independent variables as a group have no significant influence on the dependent variable (i.e., whether the right hand variables "explain" the observed variation in the left hand variable)*. Perusal of standard errors indicates that estimated parameters in the size equation ure significant at least at the .05 level, while estimates in the Rec equation are significant at the .10 level, excapt for the bank size variable, ABA. A better test of the overall significance of the estimated equation may be obtained using the reported F statistics. A table of the $F$ distribution indicates the Size equation is significant at over the .0001 level of significance while the Rec equation is siznificant at the .003 level--in each case significance levels are far in excess of the usual .05 level, Once again, the F test performed is a simultaneous test of whether all slope coefficlents estimated for the model are significantly different from zero (that is,

*Two excellent references to hypothesis testing of the type we have been discussing are Econometric Theory, A. Goldberger, John Wiley \& Sons, 1964 and Econometric lethods, J. Johnston, McGraw-Hill Book Co., 1963. 
It is a test of whether knowing the values of the independent variables would be useful in predicting the dependent variable). So, for example, the F test on the Size equatiun indicates that we are sure more than 9999 out of 10,000 that the included set of variables have a non-zero effect on the size of the loss. Of course, without infinite samples we can never be positive, but we know with, e.g., the Size cquation that we will be in error less than one time in 10,000 .

Turning to the flrst estimated equation, we find that the predicted size of loss increases wilh manigerial ranks and with the deposit size of the bank (ABA number). Here the deposit size of the bank acts as a proxy for the extent of asset exposure in various accounts. The higher the exposure, the higher the predicted 1oss, M1so on average, collusion adds $\$ 91.6$ thousand nore to the predicted loss than if the embezzlement or fraud did not involve collusion. In Table 9, we have calculated predicted losses for the cases of small, average and large banks, with and without conspiracy and by managerial position. Sinall banks were derined to be those with from three to five million dollars in deposits (ABA deposit group number 5); the average bank size in our sample hats in ABA number of between 10 and 11 and large banks were defined as banks with deposits betwecn one and two billion dollars (ABA deposit number 19). The last column of the table contains the sensitivity of the pradicted loss to changes in the size of the bank and are given in percentage (elasticity) terms. One elasticity is calculated for each bank size and each managerial position by averaging the elasticities over the two values of $\mathrm{C}$.

For the case of bank presidents, the predicted loss per attempt ranges from $\$ 115,230$ for presidents in small banks acting alone to $\$ 431,680$ for presidents in large banks in collusion with other. For top management predicted losses range from $\$ 44,040$ in small banks with no collusion to $\$ 360,490$ for those in large banks who are engaged in collusion. 


\begin{tabular}{|c|c|c|c|c|}
\hline $\begin{array}{l}\text { Predicted Lusses } \\
\text { (thousands of } \$ \text { ) }\end{array}$ & Collusion & Bank Size & Position & $\frac{\operatorname{size}}{\log A B A}$ \\
\hline$\$ 115.23$ & no & $\operatorname{small}^{1}$ & president & \\
\hline$\$ 206.84$ & yes & sma] 1 & president & .216 \\
\hline$\$ 207.74$ & no & average $^{2}$ & president & \\
\hline$\$ 299.35$ & yes: & average & president & .164 \\
\hline$\$ 340.07$ & no & $\operatorname{large}^{3}$ & president & \\
\hline$\$ 431.68$ & yes & large & president & .084 \\
\hline$\$ 44,04$ & no & $\mathrm{sma1} 1 \mathrm{I}$ & top manage. 1 & \\
\hline$\$ 135.65$ & yes & sma1l & top manage. 1 & .483 \\
\hline$\$ 136.55$ & no & average & Lop manage. I & \\
\hline$\$ 228.16$ & yes & average & top maniage. & .235 \\
\hline$\$ 268.88$ & no & lerge & top manage. 1 & \\
\hline$\$ 360.49$ & yes & large & top manage. & .104 \\
\hline$\$ 25.17$ & no & small & $\begin{array}{l}\text { low-middle } \\
\text { manighemenl. }\end{array}$ & \\
\hline$\$ 116.78$ & yes & small & $\begin{array}{l}\text { low-middle } \\
\text { managatent }\end{array}$ & .775 \\
\hline$\$ 117.68$ & no & average & $\begin{array}{l}\text { low-midd]e, } \\
\text { managetent: }\end{array}$ & \\
\hline$\$ 200.29$ & yes & average & $\begin{array}{l}\text { law-mirldle } \\
\text { managuient : }\end{array}$ & .266 \\
\hline$\$ 178.82$ & no & large & $\begin{array}{l}\text { low-middle } \\
\text { managenent }\end{array}$ & \\
\hline$\$ 270.43$ & yes & large & $\begin{array}{l}\text { low-middle } \\
\text { managmint }\end{array}$ & .149 \\
\hline
\end{tabular}

${ }^{1}$ Deposits between 3 and 5 million dollars

2 Deposits between 25 and 30 millior dollars

3 Deposits betweun 1 and 2 billion dollars

4 The perceatage change in the size of the predicted loss due to a percentage change in bank size (as measured by the $A B A$ indicator of bank deposits) 
For the low to middle management grour predicted losses range frum $\$ 25,170$ in small banks with $\mathrm{C}=0$ to $\$ 270,430$ in large banks with $\mathrm{C}=1$. The percentage response of predicted losses due to a, say, one percenc change in bank size rarges between eight hundreds of one percent for the case of large banks with the president perpetrating the fraud or embezzlenent to alnust eight lenths of one percent for the case of small banks with low to middle management being the guili.j farty. Hence, as bank stze fncreases, the amount at risk increacs and the predicled anount of losses increase but at a decreasing rate.

The second estinated equation relate: dollar athont:s recovered to nianagerial position, bank size (again measured by the $A B A$ deposit proup) and the period of time the loss was concealed. We see that absolute amounts recovured increasc with runk although the difference between top and low-middle inamagentent is rather small. Since amounts stolen pretty much increase with the position of the perpetrator we might expect this result. But, we also find that the larger the institution, and the longer the period the loss is concealed, ecterisi paribus, the lower is the predicted amount recovered, In Tabl: 10 we have calcalated predicted aniounts recovered for "small, "average" and "large" banks (using the same definitions as in Table 9) for "stort", "average" and "long" concuilnent periods. "Short" periods are 4 months, the "average" periud concealed is 18.4 months and "long" concealtrent periods are defined to be 60 months. The position variables are evaluated at their means for these calculations. 


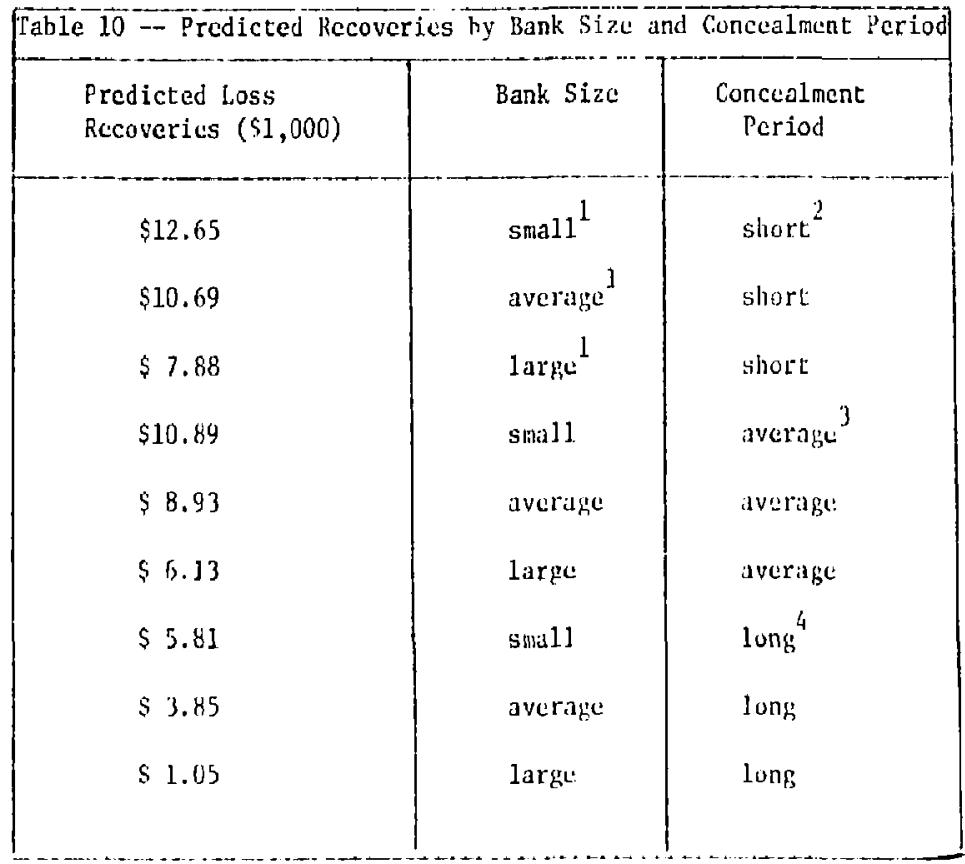

$1_{\text {Sec fuotrote at bottom of Table } 9}$

${ }^{2}$ Short $=4$ months

${ }^{3}$ Average $=18.4$ months

${ }^{4}$ Lung $=60$ inontlis

The elasticity of dollars recovered to chimges in hank si\%s is - 401 at the sample means and the analogous calculation for changes in the period a loss is concealed is -.246 . Hence a $1 \%$ increase in bank size (as measured by deposits) leads on average to a predicted decrease in the amount of losses recovered of .4 of $1 \%$ with an andlogous interpretation for changes in the period concenled. So buth the absolute size of the institution and the length of time a luss is concealed have deleterious effects on recovery rates. To the extent that the insider problem in banks is analogous to the insider problem in nuclear facilities "time is of the essence", since chances of material recovery will decrease with the time the loss goes underected. 
The Distribution of Bank Fraud and Emberzlement Losses and the Frequency of 0ccurrence

In this section we utilize the FUIC record of $8 \mathrm{~F} \& \mathrm{E}$ losses by state and combine this information with information on the bank regulatory process and the banking salary structure within states. There are sufficient differences across states in each of these factors to permit estimation of their teffects on the distribution of lusses and on the relative inciucncy of tosses.

The Relative froquency of Occurrence -- We ace particularly interested here in assessing the effects of relative banking salaries and the rigorousness of $\mathrm{ex}-$ ternal regulatory controls on the likelihood of an umbexzlement. Data on the following variables were avaitable and used to this end.

$\mathrm{S}_{\tau}$ : average banking salarjes in a state divided hy fer capita inceme

$X$ : the number of bank examinations in the state in the previuus year divided by banking assets in the state

$M: M=1$ if state has a"financial institution cuperience" requiroment for bank examiners, $M=0$ oblerwise

$L: L=1$ if a state supplies legal staff to work with cxaminurs, $L=0$ otherwise.

$P_{I}$ : the likelihood or probability that any given insider will comnit a bank fraud or embczzlement (of an; size) in a given year.

Banking salaries are measured relative to a proxy for other salaries in the state (per capita income), $\mathrm{S}_{\mathbf{r}}$, since economic thcory tells us that it is relative wage positions of individuals which is responsible for their choices and predicts more B F \& E, ceteris paribus, the lower are relative wilget.

The number of bank examinations obviously must be normalized for the size of the banking industry in a state. Our variable $X$ measures the frequency of examinations in the recent past relative to the size of the industry, as measured by total banking assets in the state. 
The variables $M$ and $I$, are obvious in their inteapretation, although it is interesting to note that cynics both in the banking industry and associated with the banking industry have, on a number of occasions, discaunted the effectiveness of such "quility controls".

Finally, we have measured $l_{L}$, the probability per insider of a $V F$ or $E$ in a state as the ratio of the number of losses (of all sizes) in tic state in a year divided by the number of ank ang employees (thousandu) in the state in rDIC regu* lated banks. Our dati indicates that emplovees at all ranks frou filing clerks, tellers and errand boys to bank presidents activcly participate in $B E \& E$. It woult be desirahle to have information on the number of employees by position so that probabilities could be estimated for each position. He have not been able to locatu such information. Our approach here is tantamount to treating all banks in a given state as one large bank and then estimating the probability that any one employee of that bank would commit a fraud or embezzlement. The probability equation, $P_{L}$, was estimated using data for 1975 only, due to a lack of information on $M, L$ and $X$ for other years. Also infornation is available on the total number of banking employees in the state and not on the number: of banking employees in FDTC regulated institutions. To account for the difference in populations from which the numerator and denominator of our probability measure are taken we have assumed that the number of employees in a bank is proportional. to the assets of the institution--an assumption, that with a few exceptions, seems to be quite reasonable. As we noted at the outset, FDIC was responsible for regulating $25 \%$ of total deposits in the U.S. in 1973. Since hanking assets are proportional to deposits, we have used $25 \%$ of total banking employees in a state as the number of banking employees in FDIC regulated institutions. The estinated equation is

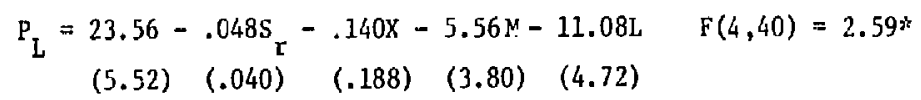

There are 40 degrees of freedon instead of 50 due to incomplete data on ten states. Also, note that the predicted value of $P_{L}$, for any given set of values for for $\mathrm{Sr}, \mathrm{X}, \mathrm{M}$ and $\mathrm{L}$, must be multiplied by .001 since the number of banking employees in states is measured in thousands. 
As before, standard errors are recorded in parentheses beneath estimated coefficients. A1though perusal of these errors indicates that significance levels are relatively low here, except for the "legal support" variable, the calculated F statistic indicates that the equation is significant at the .05 level of significance. For this reason, we have reported our estimate, jut it should be kept in mind that we are less sure of the magnitudes of coefficients than we would like to be.

Notice that the coefficients of $X, M$ and $L$ imply that regulatory controls do have deterrent effects. The more bank examinations in the prior year, the existence of ninimal examiner standards and the existence of a legal staff at examiners' disposal al.1 lead to lower predicted probabilities of $B$ E \& E. Also note that high wages in batiking relative to other occupations leads to lowered chances of B F \& E.

Our predictions for the probability that any given outsider will comnit a $B F$ or $E$ are reported in Table 11 for several interesting cases. First, at the sample means we find that there are approximately 7.6 chances in one thousand. T'he sample means represents a hypothetical "average state" that has the sample average relative banking salaries, the sample average number of bank examinations, etc.* Ninety five percent confidence intervals for this probability are $(.0067, .0085)$. In other words, we are $95 \%$ confident the true value of $\mathrm{P}_{\mathrm{L}}$, at the sample means, lies between 6.7 chances in one thousand and 8.5 chances in one thousand.

\footnotetext{
*A1though $M$ and $L$ are dichotomous variables, their means may be intepreted as representing intermediate levels of financial institution experience and legal staffing which occux in the hypothetical average state; (i.e., convex combinations of individual state values for $\mathrm{M}$ and $\mathrm{L}$ ).
} 


\begin{tabular}{|l|c|c|c|c|c|}
\hline Table 11 - Predicted Frequencies of Bank Fraud and Embezzlement \\
(per year):
\end{tabular}

Moving down the rows in Table 11, we see that, ceteris paribus, if the "average state" went [rom a regulatory climate in which mininal scandards were required for examiners to a climate of no minimal standards, the predicted probability that any

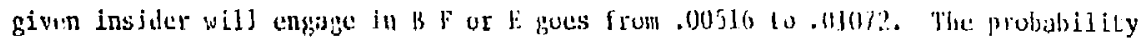
note than doubles! Next consider the same state which in the past has always supplied legal support for state banking examiners. Now assume that such support is terminated. Our estimate of $P_{L}$ then goes from 5.36 in one thousand to 16 in on thousand--tripling the risk of an incident. The limited information in the sample appears to strongly support the notion that bo:h minimal experience requirements and legal support are quite effective in deterring $\mathrm{B} F \& \mathrm{E}$.

We have also calculated the elasticity of $\mathrm{P}_{\mathrm{L}}$ with respect to both relative banking salaries, $S_{x}$, and the relative frequency of examination, $x$. At the sample mean, these numbers are -.225 and -.298 , respectively. So a one percent increase in the wages of banking employees relative to wages in the rest of the "average state"leads to a .225 per cent decrease in the chance per insider of a B F or E, with a similar interpretation for an increase in bank examinations. 
The Distribution of Loss Size--Using the same information as in the previous section we have endeavored to explain the distribution of losses across states. In particular we have estimated equations that yield considerable insight into the mean and scandard deviation of state wide losses due to $\mathrm{F} \& \mathrm{E}$. As above, the necessary information was available only for 1975.

Two new variables have been utilized In our estimation, $\bar{s}$--average banking sataries in a state (dollars) and $N_{r}$ the number of banking employees relative to the size of the banking lndustry, as measured by total banking assets, (The number of employees is measured in thousands, banking assets in billions of dollars.) Hence, the number of banking employees is divided by state banking assets to yicld " ${ }_{r}$, a measure of employee concentration. Mean B F \& E losses (per case) in a state are denoted ML (dollars) and the standard deviation of loss size is denoted SL (dollars). The estimated equations are

$$
\begin{aligned}
& \begin{aligned}
M_{1}= & 764.21-8.88 \bar{S}-293.69 N_{\mathrm{T}}-4.61 \mathrm{~K} \\
& (169.75)(3.84)(91.45) \quad(2.96)
\end{aligned} \quad[3(3,41]=4.19 \\
& S L=1587.94-18.55 \bar{s}-593.89 \mathrm{~N}_{\mathrm{r}}-12.69 \mathrm{X} \quad \mathrm{r}(3,41)=4.51 \\
& \begin{array}{llll}
(354.48) & (8.02) \quad(190.98) \quad(6.18)
\end{array}
\end{aligned}
$$

As usual standard errors appear in parentheses bencath estimated coefficients. All coefiticients are statistically significant at least at the .05 level. The computed fis statistics have three and forty one degrees of Erecdum thaking the first equation significant at the .01 level and the second significant at the .008 level. The included variables are importint determinants of the mean and variability of losses. Notice that coefficient signs are identical in both equations. So policies that decrease mean losses also decrease the variability of losses. States with relatively high salaries in the banking industry, ceteris partbus, have both lower expected losses and more certainty as to the size of losses. The sane is true for bank examinations. 
The more examinations, ceteris paribus, the lower are mean losses and the less variability is there in losses. The last variable in the equations is $\mathrm{N}_{\mathrm{r}}$ and indicates that as the number of employees increase, everything else remaining the same, that mean losses and their variability fall dramatically. Apparently there are strong economies of scale in the policing and detection of dishonest employecs. So if several organizations are identical except in the number of employees, our estimates indicate that the size of the mean lass will be absolutely (not relatively) lower in larger organizations, as will the variability of the loss size.

To get a better feeling, quantitatively, as to the extent of the influence of each of these variables on the mean and variability of losses, we have calculated elasticities at sample means for each variable. For $\overline{\mathrm{S}}$ we find that a one percent increase in average salaries leads to a .52 per cent drop in predicted losses and a .56 per cent drop in predicted varlability. One per cent increases in the number of bank examinations (holling assets constant) leads to a predicted reduction in the mean size of losses of .43 per cent and a drop of .61 per cent in the predicted variability of loss size. Finally, a one per eent incrcase in the number of employees, in a given banking structure, leads to a predicted drop in mean losses of 2.43 per cent and a predicted drop in the anount of uncertainty surrounding the size of losses of 2.54 per cent.

The moral to the story we have been telling in this section is that, all else being the same, large organizations as measured by the number of employees are much better at policing or in general overseeing employees than are small organizations. No doubt some of this advantage stems from the personal autonuny which exists in large organizations. Siltall organiza: ions tend to treat cmployces as "family" which can cause problems. The other advantage of large organizations stems from the division and specialization of labor devoted to detection of B F S E. Large organizations have, as a rule, internal auditors and often a well-defined and thought out system of controls which are usually non-existent in small banks. 


\section{THE EXTERNAL THREAT (Aircraft Hijackings and Hostage-Type Terrorist Events}

In what follows we examine two different types oi external threats to the viability of institutions which, each in their own way, is in scme sense, analogous to the external threat facing nuclear facilities. The first set of data pertains to aircraft sky jacking incidents in the period from 1961 to the present. Thesc data are analyzed rather exhaustively and yield a number of interesting results. The second data set pertains to termorist activities in which hostuges are used as a means of extracting demands. Our results here afe preliminary but nonetheless have interesting implications. A much more detalled analysis of this latter data set is planned for a future study.

\section{Airuraft Hijacking}

The security problem confronting airlines and the federal agencies responsible for airline safety and performance is similar in many respects to the problem confronting operators of nuclcar facilities and NKC. In patticular, the macro problen is designing an operating system that delivers a specific connodity with a high degree of dependability and at low risks to the public at large. Vatil the advent of epidemic aircraft hijackings in the late sixties, it seemed that $\mathrm{CAB}$ and FAA had reasonably well accomplished the stated goals as they pertain to air carriers. At that time, the dramatic increase in hijackings caused carriers and regulators to completely rethink the assumptions day to day airline operations had been based upon. And within a few years, following a number of policy changes, hijackings (at least domestic hijackings) had dropped of $f$ as dramatically as they had increased. The policy changes of interest were changes in operation procedures which led to significant increases in the chances a hijacker would be unsuccessful; changes in law which led to increases in prison sentence lengths (and, by the way, much more certainty as to the length of sentence one would receive if one were cauglit); and in January, 1973, changes in aircraft boarding procedures which entailed mandatory screening of all 
passengers and carry-on luggage at U.S. airports. Finally, the probability a potential hijacker would be killed in the act increased appreciably over the sainple period.

Many of the policy changes we have listed are the result of close cooperation between the airline industry and FA. Others are the result of increase: public awareness of a serious problem and legislative esponse to a visibje public concern. In the analysis that follows we have s rted at the effectiveness of ach of the policy changes mentioned in dealing with the aircraft hijacking problem. Among others, one value of such an analysis is to supply the necessary information to do a cost-benefit analysis to determine where the regulatory agency's dollar has the most impact in dealing with the hijacking threat. For example, how much of the resources of the agency should be funneled into either buying or promoting physical screening devices, how much into lobbying to try to change the severity of punishment, how much into, say, internal training programs that increase the probability of failure once an event is under way, cte.? It is to these and other questions that we now turn.

The data used in our analysis was supplied by liA and is available as chromology of Hijackings of U.S. Ncgistered Aircraft and Current Legal Status of Hijackers. Variable definitions and units of méasurement follow:

H: total number of connercial U.S. registered planes which were hijacked in a given quarter

$\mathrm{P}_{\mathrm{a}}$ : probability that a lijacker will be captured (arrested)

$\mathrm{P}_{\mathrm{c}}$ : probability that a hijacker will be convicted given he is alrested

$\mathrm{P}_{k}$ : probability that a hijacker will be killed in the act

$M_{s}$ : the mean prison sentence length (years) for hijacking

$\mathrm{SD}_{s}$ : the standard deviation of prison sentence lengths (years)

C: U.S. personal (real) consumption (billions of dollars)

Observations were available on most of these variables for 190 incidents in the 
period 1961-1977. We aggregated observatiuns into the $6 ;$ quarters in this period. The variable $P_{a}$ was measured as the total number of alrests in the current and prior quarter divided by the total number of hijackings in the two quarters. (If more than one person was involved in a hijacking we used the proportion of those who were arrested.) We have used an average value oner two quarters for $\mathrm{P}_{\text {id }}$ as work in other areas Indicates that an individuals' perceptions of reality don's change itniediately but are continually adjusted to gradually account for new information. The probabillty of belng convicted given that one is artested is measured as the number of hijackers convicted in the current and prior quarter divided by the cotal number of arrests in the two quarters. (The case of muItiple perpetrators was handled as with $\mathrm{P}_{\mathrm{a}}{ }^{\text {.) }}$ The variable $p_{k}$ is the number killed divided by the numbar of lijackings--again over the two most recent quarters and with the same inultiple perpetrator convention. The mean prison sentence $M_{s}$ is the average sentence length meted out for hijacking an aircraft in the current or prior quarter. The same time period appiies to the standard deviation of sentente lengths. 'The tatter variable neasures the deygece of certainty with which a potential hijacker can expect to receive the mean prison sentence if he fails. There is much literature in different areas of econonics which sugges ts that the degree of certainty in each of the aspects of a risky decision is an inportant determinant of whether or not the decision will be taken. Of course $P_{a}, \Gamma_{c}$ and $P_{k}$ each measure other aspects of the uncertainty involved in the hijacking decision. We would expect, for example, that everything else being the same, many individuals would be more likely to hijack an aircraft the larger is $S_{s}$. That is, many individuals will be risk takers in sentence lengths. This is expected berause stntence length unlike wealth is a "discommodity"--something one would rather have less of than more of, Being willing to gamble with a discommodity is analogous to not being willing to gamble with a commodity. Finally the variable real personal consumption is included as a crude measure of how well of $f$, economically, the population is. Since hijackers as a whole have been "losers", we would expect that if consumption levels of "losers" stay approximately constant at low levels, then the higher is $C$, the higher will be 
the hijacking threat,* So $C$ is an attempt to measure the disparicy in "well-being" between the lawer segments of society and the remainder. Of course, this should not be taken to mean that every aircraft hijacker falls into this class, since this is clearly not the case. But if one accepts the hypothesis that the cconomic well being of the lower segments of society is rather static, then real consumption levels are probably a reasonable proxy for the alienation of this group. (Clearly, not all "losers" are economic "losers", although a good portion art. In any event, data are available on ecnnomic variables which may proxy for the alienation of certain groups. Other alienation proxies are certainly possible, but would be much more difficult lo measure.)

Of the 190 aircraft hijacking incidents in our sample, cighty per cent represent the work of a single individual. The distribution of perpetrator group size is shown in Table 12.

\begin{tabular}{|c|c|c|c|c|c|c|}
\hline Number in Group & I. & 2 & 3 & 4 & 5 & 6 \\
\hline Number of Cases & 149 & 23 & 12 & 3 & 2 & 1 \\
\hline
\end{tabular}

*See, for example, Federal Aviation Administration's Behaviolal Rescarch Program for Defense Against Hijacking, Dr. Evan Pickrel, HM, 1974, who noces that "Hijackers as a group are failures." 
Our interest in this portion of the study centers on the equations we have estimated relating hijacking of U.S. originating fights to ce: tain determinants of these cvents. We have focused our attontion on U.S. registered aircraft primarily for the reason that data tends to be more complete and more accurate for this group of carriers. The estimated equation is

$$
\begin{aligned}
H= & 8.26-11.44 \mathrm{P}-3.67 \mathrm{P} \\
\mathrm{c} & -.086 \mathrm{M}_{\mathrm{s}}+.188 \mathrm{SD} \mathrm{s}_{\mathrm{a}}+.012 \mathrm{C}
\end{aligned} \quad \mathrm{P}(5,59)=14.65
$$

As usual standard errors of the estinated coefficients appear in parenthesis beneath the coefficients. The F statistic implies the estimated equation is significant at greater than the one in ten thousand level of significance and each individual estimate is significant at least at the .05 level. There is little dubt that the included variables are among the nore important determinants of quarterly aircraft hijackings. We find little that is unexpected in the estimated equation. Probabilitics of capture and conviction conditional on capture have significant deterrent effects on potential hijackers as do increases in the length of prison sentences. As we discussed above, real consumption levels should have a positive effect on the number of hijackings if consumption levels measure what we have supposed--the disparity in economic "wellbeing" between lower segments of society and the rest of the population. And as our estimate indicates, this is indeed the case. Of course there is some problem in knowing which country's or group of countries' corsumption levels should be used in the estimation. Since a great many of the hijackings occurred in the U.S. and advanced nations, we decided to use the U.S. data as a proxy for consumption levels in this group of nations.

Notice that $\mathrm{P}_{\mathrm{k}}$ does not enter the estimated equation and appeared throughout our analysis not to have a significant inpact on the number of hijackings. Nonetheless, we feel that it is probably incorrect to infer that the chances of being killed in the act of hijacking an aircraft has little or no effect on the decisions of potential hijackers. Instead, it is most likely that the sparseness of incidents in which perpetrators were killed in the act is responsible for the insignificance of $P_{k}$. 
of the 190 incidents in the sample, only in nine were hijackers killed, which probably dees not provide sufficient variation for paraneter estimation.

The remaining variable so enters with a positive cueficient as expected indicating that hijackers as a group are risk takers with respect to sentence lengths. To get a better feeling for the relative imact of each of the independent variables upon the number of dircraft hijackings we have calculated the elasticities of hijackings with respect to each of the variables. The calculated functions were evaluated at the sample means and are listed in Table 13.

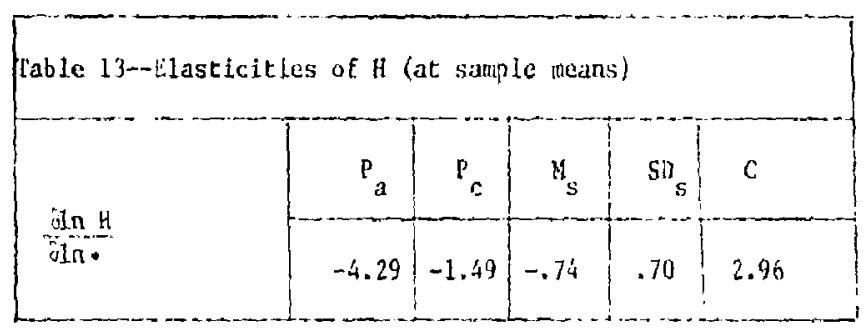

Notice that the probability of arrest (failure) has a greater impact on the predicted number of hijackings than any other variable--a one percent increase in $P_{a}$, from .80 (the sample mean) to roughly .81 , resulis in a predicted 4.29 percent decrease in hijackings. Percentage changes in the probability of being convicted, given a hijacker is captured, also have significant deterrent effects at 1.49 percent per one percent change in $\mathrm{P}_{\mathrm{C}}$. Increases in the mean sentence length and decreases in the uncertainty surrounding the centence length lead to roughly .7 of one percent decreases in predicted hijackings per one percent changes in $\mathrm{M}_{\mathrm{s}}$ and $\mathrm{SD}_{\mathrm{s}}$. The more certain the sentence and the longer the length, the lower the number of prodicted hijackings. The data strongly supports the propusition that hijackers on average, find it increasingly disadvantageous to hijack aircraft as the certainty of serving the mean sentence increases. Finally, increasing general consumption levels relative to the 
"worst of $f^{\prime \prime}$ in society causes rapid increases in predicted hijackings--roughly 3 per cent per one per cent change in C.

To give the reader a more graphic feeling for the effectiveness of altering the probability of capture as a policy for corrating this type of terrorism, we hive presented in Table 14 predictions of the number of guarterly hijackings for (i) the "average" quarter in the sample; (ii) for the "best case", where $P_{a}$ is at its sample maximun, other variables taking on their sample average; and (iii) the "worst case" where $P_{a}$ is at its sample minimum, other variables being evaluated at sample means. The predictions are interest in $i^{\prime}$. At the sample mouns the prodicted

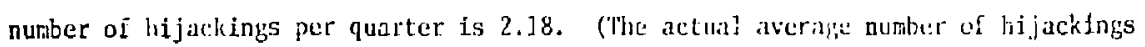
per quarter is 2.38.) We have defined the "best case" for the othervise "average quarter" as a quarter with mean consumption levels, mean prison santence characteristics and mean $P_{c}$ but sample maximum values for $P_{a}$. The predicted number of hijackings for such a quarter is zero. For the worst case we have used the mininum sample value of $\mathrm{P}_{\mathrm{a}}$ all other variables remianing at the sample neims. Predicted hijackings in this case are 8.01 per quater.

\begin{tabular}{|c|c|c|c|c|c|}
\hline $\begin{array}{c}\text { Table 14-Predicted lij ackings: } \\
\text { Quarter }\end{array}$ & $\mathrm{P}_{\mathrm{a}}$ & $\mathrm{P}_{\mathrm{c}}$ & $\mathrm{M}_{\mathrm{S}}$ & $\mathrm{SD}_{\mathrm{S}}$ & $\mathrm{C}$ \\
\hline 2.18 & mean & mean & mean & mean & mean \\
\hline $0^{*}$ & miax & mean & mean & mean & mean \\
8.01 & min & nean & mean & mean & nean \\
\hline
\end{tabular}

*Predicted hijackings are -. 108 which is mol siguicticutly different from zero.

Examination of the quarterly hijacking series shows that hijackings were at a very low level from 1961-1967, thon rise very rapidly during the period 1968-72 and then fall precipitously after 1973, where they have remained until the present. Also beginning roughly in 1973 , we find a period of rapidly rising probabilities 
of capture and conviction given capture and steadily increasing prison sentence lengths. At the same time (January 1973) the eAd mandated physical screening of boarding passengers and their luggage was begun. An inturesting question zonccorns the 1mpact of the increased probabilities of failure ( ${ }^{\prime}{ }_{a}$ and ' ') and increasced prison sentences relative to the impact of increased airport security due to screening. of course the data shows only "ex post" deterrent effects--probabilities of arrest and probabilities of conviction given arrest given that an individual has been screened. The data do not indicate the level of deterrence provided by the very existence of boarding area screening devices, so called "ex unte" deterrence. Surely many potential hijackers have been deterred merely by the existence of screening procedures in boarding areas, all under the wilchial eye of armed guards.

To estimate the marginal impacts of ex post and cx ante detcrent effects, we have re-estimated the hijacking equation using only the pre-screening sample, that is, that purtion of the sample corresponding to the period 1961-72. The estimate is

$$
\begin{aligned}
& H_{x}=-1.06-10.15 \mathrm{P}_{\mathrm{a}}-4.01 \mathrm{P}_{\mathrm{c}}-.032 \mathrm{M}_{\mathrm{s}}+.075 \mathrm{SD}+.031 \mathrm{C} \quad \mathrm{F}(\mathrm{s}, 39)=16.42 \\
& \begin{array}{llll}
(2.12) \quad(4.12) \quad(.065) \quad(.172) \quad(.007)
\end{array}
\end{aligned}
$$

Here we have used $\|_{x}$ to denote domentic hijackings per quarter without the influence of boarding area screening. (The 1961-72 time period). igilin the equation is highly significant at more than the .0001 level. One means of sorting out the impact of screening from the impact of changes in sanction and probability levels is to use the $H_{x}$ equation to predict quarterly hijackings over the 1973-77 period--that is, to predict the number of hijackings as if there were no screening. Merely substituting the actual values of $\mathrm{P}_{a}, \mathrm{P}_{c}, \mathrm{M}_{\mathrm{s}}, \mathrm{SD}$ and $\mathrm{C}$ into $\mathrm{H}_{\mathrm{x}}$ for each quarter commencing with the first quarter of 1973 and predicting quarterly hijackings does precisely this. Increased deterrence from increased values of $\mathrm{P}_{\mathrm{a}}, \mathrm{P}_{\mathrm{c}}$ and $\mathrm{M}_{\mathrm{s}}$ have been accounted for, but the impact of screening has been excluded. These predictions are shown for 
each quarter in column 3 of Table 15. Subtraction of the actual number of hijackings in each quarter, column 2, from these predictions yields an estimate of the reduction in hijacking attributable soley to physical sciening and is given as column 6 in the table. Table 15, column 4, contains predictions for the quarterly

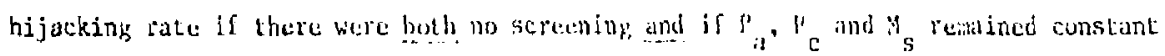
at their 1972 levels. These figures were obtained merely by cvaluating ${ }_{x}$ using mean 1972 values for $\mathrm{P}_{\mathrm{d}}, \mathrm{p}_{\mathrm{C}}$ and $\mathrm{M}_{\mathrm{s}}$ and allowing other variables to take on their actual values. Hence column 4 contains quarterly predictions of hijackings that would have occurred if the status quo were maintained in 1972: in particular if there had not becen increased enforcement and bourding areat screaning was not introduced. The difference between these prodictions and actual hijackin; rates (column 2) is an cstimate of the total impact of screening and incruased inforcement (increasing $P_{a}, P_{c}$ and $M_{s}$ ) on the hijacking threat. Of course subtracting column 3 from column 4 (or column 5-column 6) yields the predicted reduction in hijackings due solely to changes $P_{a}, P_{c}$ and $M_{s}$ and is shown in column 7 of the table, Finally, in column 8 we have assessed the relative importunece of screming in the total deterrence picture by calculating the predicted reduction in incidents due to boarding area screening divided by the predicted reduction in incidents due to increased enforcement plus screening. On average over the 1973-77 period, boarding area sureening accounts for $66 \%$ of the total predicted reduction in incidents due to all polfcy changes undertaken. Hence one thiro of the reduction is due to increases in $\mathrm{P}_{\mathrm{a}}, \mathrm{P}_{\mathrm{c}}$ and $\mathrm{M}_{\mathrm{s}}$. By way of summary, the predicted number of hijackings with neither screening nor increased enforcement (column 4) averages 6.96 per quarter for the 73-77 period. The predicted number per quarter averages 5.01 if enforcement variables take on their actual values but screening is not introduced (column 3). Finally, the average reauction due soley to enforcement (column 7) is 1.95 per quarter and the average reduction due soley to screening (columa 6) is 4.10 . 
Table 15 - The Relative Importance of Screening vs. Changes in $P_{a}, P_{c}$ and $M_{s}$ in Deterring Hijackers

\begin{tabular}{|c|c|c|c|c|c|c|c|}
\hline $\begin{array}{c}1 \\
\text { Date } \\
\text { qtr/yr }\end{array}$ & $\begin{array}{c}2 \\
\text { Actual } \\
\text { Hijackings }\end{array}$ & $\begin{array}{c}3 \\
\text { Predicted } H_{x} \\
\text { (all ind. } \\
\text { var.assume } \\
\text { actual values) }\end{array}$ & $\begin{array}{l}4 \\
\text { Predicted } \mathrm{H}_{\mathrm{x}} \\
\text { (same as } \\
\text { col. } 3 \text {, but } \\
\mathrm{P}_{\mathrm{a}}, \mathrm{P}_{\mathrm{c}} \text { and } \mathrm{M} \\
\text { at I972 } \\
\text { means) }\end{array}$ & $\begin{array}{c}5 \\
\text { Reduction in } \\
\text { Hijackings } \\
\text { from a11 } \\
\text { sources } \\
\text { (col.4-col. 2) }\end{array}$ & $\begin{array}{c}6 \\
\text { Reduction 1n } \\
\text { Hijackings } \\
\text { duc to } \\
\text { screen1ng } \\
\text { (col. } 3-\operatorname{col} .2)\end{array}$ & $\begin{array}{c}7 \\
\text { Reduction in } \\
\text { Hijackings } \\
\text { due to } \Delta P_{a}, \\
\Delta P_{c}, \Delta M_{S} \\
(\operatorname{col} 1.4-\operatorname{col} 1.3)\end{array}$ & $\begin{array}{c}8 \\
\text { Relalive } \\
\text { Importance of } \\
\text { screcing } \\
(\operatorname{col} .6 \div \operatorname{col} .5)\end{array}$ \\
\hline $1 / 73$ & 1 & 5.44 & 5.63 & 4.63 & 4.44 & .19 & .95 \\
\hline $2 / 73$ & 0 & 7.08 & 5.77 & 5.77 & 7.08 & * & \\
\hline $3 / 73$ & 0 & 3.66 & 6.45 & 6.45 & 3.66 & 2.79 & .56 \\
\hline $4 / 73$ & 0 & 5.03 & 6.56 & 6.56 & 5.03 & I. 53 & .76 \\
\hline $1 / 74$ & 2 & 2.43 & 5.05 & 3.05 & .43 & 2.62 & .14 \\
\hline $2 / 74$ & 0 & 4.70 & 6.04 & 6.04 & 4.70 & 1.34 & .77 \\
\hline $3 / 74$ & 1 & 5.00 & 0.06 & 5.66 & 4.00 & 1.66 & .70 \\
\hline $4 / 74$ & 0 & 5.47 & 6.25 & 6.25 & 5.47 & .78 & .87 \\
\hline $1 / 75$ & 3 & 5.01 & 6.19 & 3.19 & 2.01 & I. 18 & .63 \\
\hline $2 / 75$ & 3 & 2.76 & 6.75 & 3.75 & ix & 3.99 & \\
\hline $3 / 73$ & 1 & 4.60 & 7.31 & 6.31 & 3.60 & 2.71 & .57 \\
\hline $4 / 75$ & 0 & 4.36 & 6.91 & 6.91 & 4.36 & 2.55 & .63 \\
\hline $1 / 76$ & 0 & 3.95 & 6.45 & i. 45 & 3.95 & 2.50 & .61 \\
\hline $2 / 76$ & 0 & 4.44 & 6.95 & 6.95 & 4.44 & 2.51 & .63 \\
\hline $3 / 76$ & 1 & 4.96 & 7.37 & 6.37 & 3.96 & 2.41 & .62 \\
\hline $4 / 76$ & 1 & 5.95 & 9.09 & 8.09 & 4.95 & 3.14 & .61 \\
\hline $1 / 77$ & 1 & 4.73 & 8.40 & 7.40 & 3.73 & 3.67 & .50 \\
\hline $2 / 77$ & 1 & 7.22 & 8.18 & 7.18 & 6.22 & .96 & .86 \\
\hline $3 / 77$ & 1 & 7.67 & 8.51 & 7.51 & 6.67 & .84 & .88 \\
\hline $4 / 77$ & 2 & 5.73 & 8.69 & 6.69 & 3.73 & 2.96 & .55 \\
\hline
\end{tabular}




\section{Probability of an Aircraft Hijacking}

The equations we have estimated and reported above yield predictions for the number of hijackings per unit of time as functions of certain explanatory variables. It would be desireable to be able to estimate the probability of thase incidents as functions of the same set of explanatory variables. The reason this cannot easily be done is that our sample contains but a subset of the choices made by would-be hijackers-- those cases in which the shoice was to actually commit the offense. all the remaining cases when potential hijackers decided not to go aliead with the hijacking are, of course, missing. It is this latter set of choices that would be needed to do a rather straight forward estimation of the probability of a hijacking. This situation confronts econometricians regularly and is known as the problem of a "chnice-based" sample.

A decidedly second best approach, but one which can be done, is to assituc that all commercial flights are equally likely to be hijacked. Since data arc available on the number of flights (departures) per quarter one could fit an eqquation with the number of hijackings divided by the number of departures in the quarter as the dependent variable. The saterpretation of the estimated equation would be that it is a prediction of the probability that any given flight (or a randomly chosen flight) would be hijacked in the quarter as a function of the same explanatory variables as above.* In this case the estimated equation is

$$
\begin{aligned}
P_{H}= & 6.62-9.33 P_{a}-2.97 P_{c}-.068 \mathrm{M}_{\mathrm{s}}+.162 \mathrm{SD}_{\mathrm{S}}+.010 \mathrm{C}
\end{aligned} \quad \mathrm{F(5,59)=13.65}
$$

where $P_{H}$ is the probability that a randomly selected flight will be hijacked in a quarter, measured as noted above, and where each estimated coefficient and standard error has been multiplied by $10^{6}$. Again, the estimated equation is statistically

*This is essentially the approach taken above in estimating the $P_{L}$ equation--the probability of a loss greater than $\$ 10,000$. There again we have in the sample only those individuals who actually committed B F or E. Potential embezzlers who chose not to try their luck are, of course, not in the sample. 
significant at a level greater than one in ten thousand and all individual parameter estimates are significant at least at the .05 level. Elasticities evaluated at sample means are quite similar to those reported for the $H$ equation above. At the sample means, the predicted probability that any given fiight will be hijacked in a quarter is 1.89 in one million or 7.56 in one million per year. (Over the sample period, 1961-77, there are an average of roughly a million flights per quarter.) The nincty-five percent confidence interval on $\mathrm{P}_{i 1}$, at sample means, is $(1.32,2.36) \times 10^{-6}$ per quarter.

In concluding this section of the report several comments should be made. First, the deterrent effects of changes in enforcement and penalties that we have reported depend heavily upon communicating the Jevels of these policy variables and changes in their levels to the population at large. In other words, it is the perceived size of the change in these variables that determines the magnitude of deterrent effects--not the actual size. So even if an agency has a vigorous enforcement program and has sucreeded in having legislatict enacted that elicits severe penalties, if potential adversaries are ignorant of the facts, the number of incidents (attempts) will be higher than need be. The only caveat which need be added is that the communicated enforcement policy and penalty structure must be credible if the communicated "state of the world" is to becone the perceived "state of the world" to potential adversaries. Over the long haul this implies a reasonable congruence between communicated sanctions and enforcement levels and actual sanctions and enforccment levels.

To illustrate using the case at hand, FM had postcrs made to communicate to potential hijackers that such acts are illegal and to describe the punishments which would be invoked if one attempted to hijack an aircraft (and was unsuccessful), These pusters were pisced in all passenger terminals in the U.S. At the same time, FAA also began a vigorous campaign in newspapers describing what happened to those 
hijackers that went to Cuba. (Castro didn't like them.) A number of people at FAA are convinced that these tho programs alone were responsible for a considcrable drop in the number of attempted hijackings.

In addition to these programs, in 1971 FM began a training program for airline flight personel. The objective of the training progran was to stop hijackers at the boarding gate; or if they got througl the boarding gate, training focused upon stopping them in the cabin; and for those naking it into the cockpit the training focused upon the role the cockpit crew should play in defeating the adversary there. If such a training program is effective, the result of course, is an increase in $P_{a}$, the probability of failure, and the cunsequent deterrance affects.

\section{Terrorist Events with Hostages}

In this final section we report some preliminary results ubtaincel using a data set generated by combining information From the TTlikTt: (Intemal jonal Terrorism: Attributes of Terrorist Events) data tape, compiled by Ed Mickolus for the Office of Political Research at $\mathrm{CI}$, with information from International Terrorism: A Chronology, compiled by Brian Jenkins and Jancra Johnsun at kand, with supplenental information obtained from london Times and New York Times news stories of the events. These data cover the years 1969-1977. Becausc we believe the major terrorist threat, as far as nuclear facilities are concerned, will arise in situations when hostages are used as collateral in attempts to extract demands, we have focused our attention on a subset of the terrorist events covered in these data sources. The events in our sample include (i) situations where buildings, boats, etc. are seized and hostages taken and used in an attempt to extract demands; (ii) kidnappings and (iii) airline hijackings where passengers are used in an attempt to extract either financial, political or prisoner release demands. Explicitly 
excluded were aircraft hijackings where transportation, even though politically mutivated, was the primary demand. The long term use of the data base just described will be in developing a molel to "explain" hostage-type terrorist events. That is, a model which will predict the number of these events per unit time, with reasonable accuracy, as a function of certain explanatory variables.

We report below our first findings along these lines--findings which, we must emphasize, are preliminary and may be modified as we proceed in oul investigation but. "'en at this stal,', have intriguing implicitions. Before presenting these results we define the word "terrorist" is it is used by the grotips al Riand and CIA who have compiled the data sets from which we have drawn our sample. Pou:hly a "terrorist" is an individual who uses or threatens to use violence, when the action is intended to influence the attitudes and behavior of a target group wider than its immediate victims and wher the action's ramifications transcend national boundaries.

With this definition our data set of hostage-type terrorist events contains 249 events. In 144 of these events the number of perpetrotors was known. The distribution of group size over these events is shom in Table 16 . The most notable, although certalnly not surprising, characteristic of this distribution is the number $\circ f$ individuals in collusion in these hostage-type events. The average group size over these events is approximately five.

\begin{tabular}{|} 
Table 16--Distribution of Group Size for "Hostage-Type" Terrorist Events \\
\hline Number in Ciroup & 1 & 2 & 3 & 4 & 5 & $6-10$ & $11-20$ & $21-30$ & $31-50$ \\
\hline Number of Cases & 21 & 19 & 26 & 23 & 17 & 30 & 1 & 4 & 3 \\
\hline
\end{tabular}

Both the popular literature and the writings of political scientists and sociologists have often hypothesized that the number of terrorist activitics in a given 
time period is closely related to the frequency of the sime types of activities in the recent past. The hypothesis basically being that the more frequent are the events in one period, the higher is the expected number of events in succeeding periods--a contagion effect of sorts. Another popular hyputhesis has been that if media coverage were cut dow or at the least, if terrorist events were given less prominence in the media, the level of terrorist aclivity would decrease significantly. of course, the idea here is that terrorists are primarily political groups interested in dissemination of their "messiggt" to as large an audience as is possiblc. If so, the degree of success terrorist groups attribute to an incident should rise with the atnount: of publicity genorated.

We have begun our investigation into "hostage-type" terrotist events by constructing measures of the frequency of past events and of the anount of nedia coverage given to each incident in the sample. As a first cul, wa have aggregated the events in the sample into quarterly series and are interested, at this point, only in testing whether the frequency of past events and the watent of the media coverage of these svents could be helpful in prodicting the number of incidents in the "present" quarter.

We have constructed an index of media coverage by sunming the nur 'ir of column inches of coverage in the New York and London Times. Our variable Media is the total number of column inches devoted to hostage-type events in thes nevspapers in the present and previous quarters, divided by two--the average amount of coverage per quarter. To indicate the frequency of these events in the recent past we have computed the average number of days between hostage-type events in the two most recent quarters--the average period of these events in the "recent past." We have labelled this variable Period and have regressed the number of events in the "current" quarter, $N$, on it and the Media variable as a first attempt to explain these terrorist activities. Another variable or set of variables which must be included in future work are measures of the probability of success or failure. Many possibilities for measuring success and failure come to mind: The percent of incidents in which 
demands were met, the probability of being arrested if one participates in a terrorist event, the probability of being killed during the incident, etc. A fundamental difficulty in compiling measures of these probabilities is the fact that the number of individuals involved in terrorist evints is of ten not known. Therefore measures such as the percentage of those arrested or $k j$ lled cannot be used to approximate the probability of being arrested or boing killed. Other possibilitios do exist and will be explored later.

Given once again our cautionary provisu concerning the prel iminary nature of the estimites, the estimated cquation is

$$
N=\underset{(1.23)}{5.21-.082 \text { Period }+.0058)} \quad F=(2.29)=15.93
$$

As has been our custom throughout the report, standard errors of the estimated parameters are listed ander the coefficients. The coefficients of the two variables are significant at ahove the .05 level and the equation itself is again significant at better than the .0001 leve]. Hence, we are sure better than 9,999 times out of 10,000 that these two variables have a non-zero impact on the number of terrorist events in a period. The estimated equation strongly supports the hypothesis that media coverage and the frequency of events in the recent past are positively related the number of terrorist events in the "curtunt" quaiter. (Recall that the variable Period measures the average time between events in the past two quirters, hence the shorter is this time, the higher is the frequency of events in the "past" and the higher is the predicted number of cvents for the "current" period.)

In Table 17 we present predictions for the number of events per quarter, at ) the samples means, with "heavy and light" media coverage and in cases where the period of events in prior periods is "high" and "low". The sample mean 
for Media is 400 colunn inches, with "leavy" and "light" coverage defined as two standard deviations above and below the mean, respectively (992 column inches and 188 column inches). The sample mean for Puriod is 23 days, witl "iigli" and "low" being defined as one standard deviation below and above the mean, respectively." (7 days and 39 days). The last culumn of the table contains elasticities of $N$ with respect to the two independent variables, evaluated at sumple means.

Table 17--Predicted Hostage-Type Terrorist Events/Quarter: Selccted Cases

\begin{tabular}{|c|c|c|c|}
\hline $\begin{array}{l}\text { Predicted number of } \\
\text { events/quarter }\end{array}$ & Period & Media & $\begin{array}{l}\text { Elasticities of } \\
N \text { (at sample means) }\end{array}$ \\
\hline 5.34 & mean & mean & \\
\hline 8.28 & mean & heawy $^{1}$ & $\frac{\text { dnN }}{\text { dnperiud }}=-.363$ \\
\hline 4.26 & mean & light $^{1}$ & \\
\hline 6.63 & low ${ }^{1}$ & nean & \\
\hline 4.01 & hi ighl & mean & $\frac{1 \text { nit }}{\text { alniledia }}=.374$ \\
\hline
\end{tabular}

$1_{\text {See text }}$ for definitions

A one percent increase in the frequency of incidents ( a one per cent decrease in Period--the average time between events) or a one percent incresse in media coverage afforded such events both lead to a predicted increase in terrorism of a little more than one third of one percent. At the sample means the predicted number of hostage-type incidents is 5.34 per quarter. Ceteris paribus, a decrease in media coverage from "average" to "light" reduces the predicted number of events to 4.26 per quarter--a twenty percent reduction from the mean level. Holding media coverage con-

* Two standard deviations below the mean yields a negative value for Period. 
stant at its mean value and increasing the frequency of cvents (in the past two quarters) to the "high" level yields a prediction of an increase in incidents of twenty-four percent to 6.63 per quarter. Finally a slowing down of the incidence of past events to the "low" level leads to a predicted decrease in events to 4.01 per quarter--a twenty-five por cent reduction from the mean level.

Mlthough we will not venture policy recomandations on the basis of the cursory analysis we have done to this point, the rentative implications arc iatriguing. The national interest maly be best surved not only by adopting; policies wid limit the number of incidents (since these incidents not only puse al Lhreat in thenselves but also have "contayion" effects and lead to an even gratiter threat in the future) but also by adopting policies which "duwnlay" or limit niedia coverage of any itcidents which do occur. We hope to have much more to say on thase lwo points in the future.

\section{SUMARY}

1n this study we have used three different datu suts driwn from alternative "analogous" adversary situations in an attempt to cats sune light upon the nature of internal and external threats to nuclear facilitics. The first halı of our study dealt with the internal threat and utilized data collected by the Federal Deposit Insurance Corporation on bank frauds and enbezzlements. Major findings include the following: (i) The internal threat of frauds and embezzlements account for losses on average of about six timcs the magnitude of losses sustained through external threats (primarily bank robberies); (ii) There are enough Hobbs Act cases in the banking industry, about one for every fifteen bank robberies, burglaries and larcenies to cause concern among those charged with safeguarding SNM. These incidents have tended to be very effective in extracting demands; (iii) Contrary to popular belief, managers at the highest level are far the greatest risk, both with respect 
to the number of $B F \& E$ cases and the amount of losses. For example, almost one third of all B F \& $E$ cases in our sample involved presidents of banks--individuals who would undoubtedly qualify for Q clearances; (iv) Approximatcly twenty five per cent of all B F \& E cases involve collusion among insiders, the size of the colluding group ranging between two and twenty. in addition, a full fifty seven per cent of all collusion cases involve bank presidents. M1so, cases involving collusion are much more dangerous in the sense that the size of the loss is nearly double that for cases not involving collusion. The studies we cited also indicated that the incidence of collusion has been growing rapilly over the past decade, A final point regarding collusion cases is that colluding individuals are able to conceal their activities roughly fifty per cent longer than in cases where collusion is not involvec; (v) Equations were estimated linking the mean and standard deviation of $B F$ \& E losses by state to average state salaries in banking, the relative number of banking employees in states and the relative number of bank examinations in states. We found that regulatory inspections in the form of bank examinations had significant deterrent effects--in particular increased examinations lower expected losses and the variability of expected losses. In addition, the higher are banking salaries within a state, the lower are expected losses and the variability of these lusses. The data also indicated that there are significant econonits of scole in the policing and control of employees, at least with respect to $B \mathrm{~F}$ \& $\mathrm{E}$ losses. For a banking industry of given asset size, the larger the number of employees, the lower are expected losses anj their variability. So both the mean loss and the amount of uncertainty as to the size of losses are reduced with increases in banking wages, the number of bank exaninations and the number of employees; and (vi) An equation was also estimated linking the likelihood any given employee would be guilty of a $B F \& E$ to the relative number of bank examinations, wages in banking relative to other employments in the state and two variables measuring the quality of bank examinations (dummy variables indicating existence or lack of existence of (a) minimal background requirements for banking supervisors and (b) legal support staffs for examiners). We found that the higher are wages in banking relative to other 
jobs, the lower is the estimated probability of a $B F \& E$ loss. In addition, increases in the number of examinations and increases in the quality of cxaminations all were found to have significant deterient effects.

The second half of the report dealt will the extemal throit to allegedly secure enclosures and detailed results we obtained from andyzing data sets on aircraft hijackings and terrorist events with hostages. The aircraft hijacking data were used primarily to assess the effectiveness of (a) comnunicated policies designed to increase the probability of failure ( $P_{d}$ and $P_{c}$ ) and the severity of sanctions given failure $\left(M_{S}\right)$, and (b) mechanical streening devices as a deterrent force. Our findings include the following: (i) Increases in the probability of failure at the site have a major impact on the predicted level of aircraft hijackings--a one percent increase in P laading to mure than a foul perecent decrease in the predicted hijackings; (ii) Increases in the likelihood of a cunviction given a hijacker is arrested, lead to a one and one half percent decrease in predicted hijackings per one percent increase; (iii) Increises in mein prison sentence lengths and increases in the certainty with which these sentunces are surved diso lead to significant decreases in the number of hijackings; (iv) buring the period since mechanical screening devicus have been in place at U.S. airpolts, the number of hijackins has decreased dramaticilly. Our estimates indicate that roughly two thirds of the decrease in hijackings is attributable to the deterring effect of the screening devices and one third is due to the deterrent fifects of inereased likelihoods of failure and increased prison sentences during the recent past. So, as far as the external threat is concerned, a combination of plysical screening and widely communicated high chances of failure and stifí penalties for those penetrating the screening devices have proved to be quite effective in deterring potential adversaries, at least in the airline industry.

Finally, preliminary results based upon analysis of a sample of hostage-type terrorist events lend considerable support to theories which have argued that 
terrorist groups are primarily political and interested in isseminating a "message." Hence, the amount of media coveragc an cvent reccives is used as a measure of the successfulness of the event. We also fuund a significant "contagion effect" in our sample of terrorist events--the more frequeat were similar events in the recent paist, the higher was the predicted number of events for the present. Much more work remains to be done with this sumple in a future study. 
APPENDIX: DATA SETS UTILIZED (CARDS)

Data Set 1 -- BANK FRAUD AND EMBEZZLEMENTS GREATLR THANY $\$ 10,000$

This data set contains information on all bank defalcations of $\$ 10,000$ or more from January 1, 1973 to December 31,1977 as compiled by FDIC, Internal Memorandum, Bank Defalcations of $\$ 10,000$ or More.

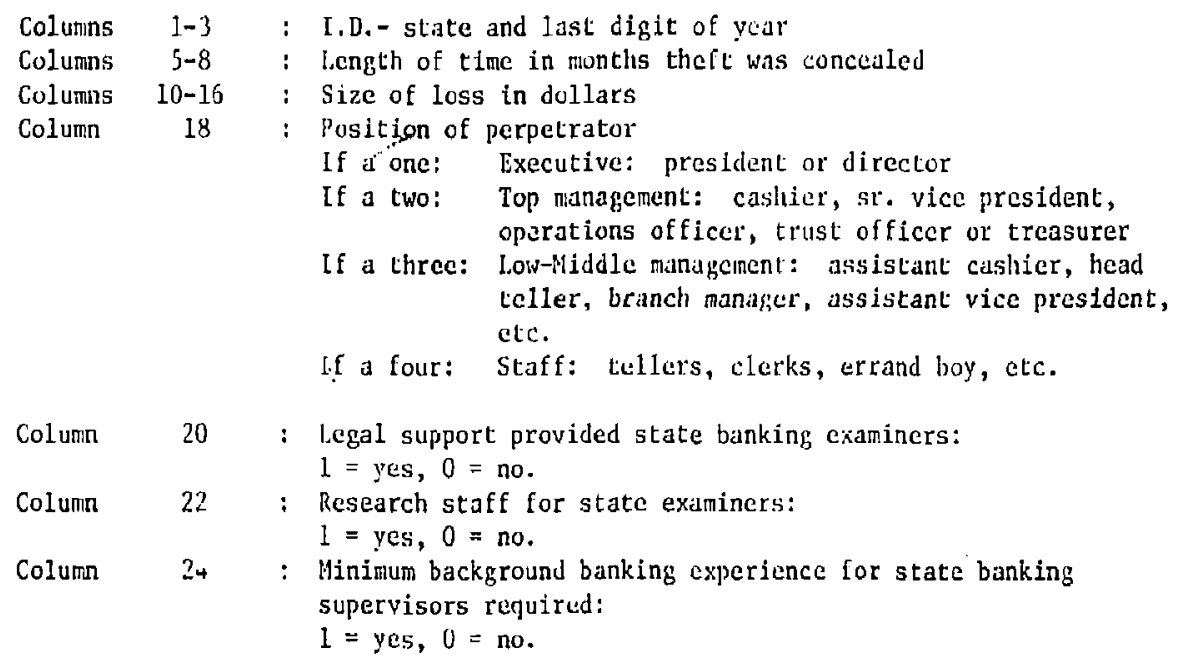

NO'TE: Coluniss 20, 22 and 24 have no infurmation for 1973, 1976\& 1977

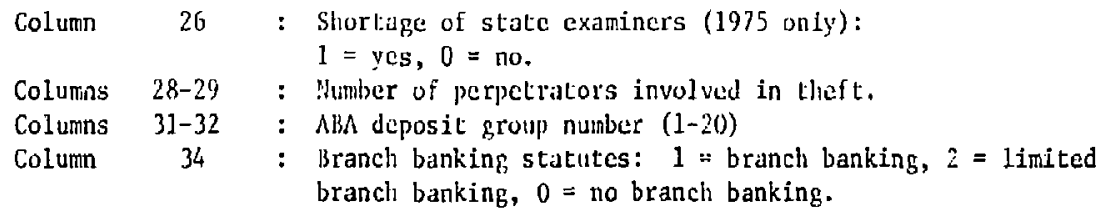

(Information in columns $20-34$ is from Profile of State Banking published by Conference of State Bank Supervisors.)

$\begin{array}{lll}\text { Columns } & 36-41 & : \text { Amount of loss rccovered (dollars). } \\ \text { Columns } & 43-47 & : \text { Number of bank employees (thousands). } \\ \text { Columas } & 49-54 & \text { : Average salary of bank employees in state (total state } \\ & & \begin{array}{l}\text { banking payroll : nunber of banking employees in state) } \\ \text { (Not available in 1977) }\end{array}\end{array}$

(The number of bank employees and banking payrolls are from County Business Patterns, U.S. Department of Commerce, Bureau of the Census.)

NOTE: $A$ dot in a column indicates information was not available. 
Data Set 2: HOSTAGE - TYPE TERRORISTS EVATS

Information on terrorist events is from International Terrorism: A Chronology 1968-1974 compiled by Hrian M. Jenkins \& Janera A. Johnson at RAND in a report prepared for Defense Advance Research Projects Agency and from the ITERATE dati tape prepared by lid Mickulus for the office of political Research at CIA.

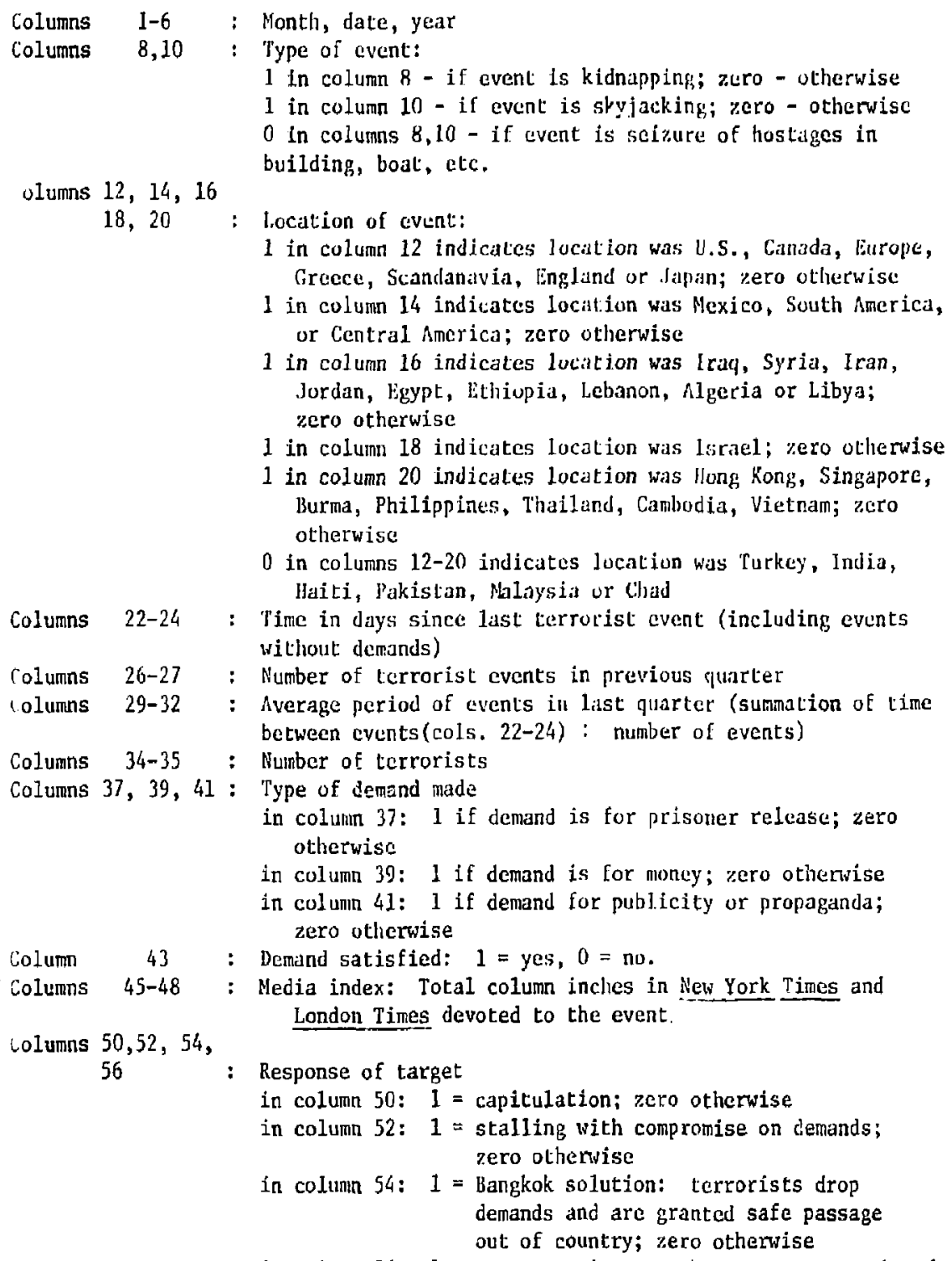

in column 56: 1 = no compromise, no shoot out; zero otherwise

If zeros appear in each colunn, response was shoot out with terrorists or nationwide search for terrorists with no compromise.

Columns 58-59 : Number of terrorists captured, including those killed.

Colums 61-62 : Number of terrorists killed, including those executed, killed during event or dead from wounds received. 
This data set includes information on ali hijackings of domestically register $d$ aircraft $i x, 5 / 1 / 61$ through $12 / 25 / 77$. Al1 information was acquired from the Chronology of Hijackings of U.S. Registered Aircraft and Current Legal Status of Hijackers compiled by the Federal Aviation Administration-Civil Aviation Security :ervice.

Columns $\quad 1.6$ : The month, date and year of each hijacking

Column $u \quad:$ The type of aircraft involved in each hijacking 1 = commercial aircraft, 0 = general dviation aircraft

Column $\quad 10$ : Registration of the carrier involved in the hijacking 1 = for a U.S. carrier, zero for a non U.S. carrier (Only two aircraft in data set were non-U.S, registered.)

Columns 12-15 : Age (or mean age if more than one) of the hijacker(s). (If the ages of any individuals were not known, those individuals were disregarded in the calculations.)

Columns $17,19,21$ : Race of the perpetrator(s) Column 17: Latin $=1$; zero othenvise Column 19: White $=1$; zero otherwise Column 21: Black = 1; zero otherwise

NOTE: On $7 / 2 / 71$ and $6 / 2 / 72$ hijackings occurred with a latin and a white and a white and a black, respectively. In these two cases there are ones in both columns. On $6 / 27 / 74$, there were two whites and one "other race" involved in a hijacking. For this incident a onc is in column 19.

Columns 23-27 : Profile of Hijacker. A one indicates the FAl profile was met or probably net. A zero means it was not met, and a dot means it was not applicable or not avajlable. $\Lambda$ number less than one is the proportion of perpetrators (if more than one) who met or probably met the profile.

Columns 29,31 : Goal of hijackers $A$ one in column 29 indicates the goal of the perpetrator(s) Was extortion: zero otherwise $\Lambda$ one in column 31 indicates the goal was political (e.g. prisoner release or propanda); zero otherwise

Zeros in both columns indicates the goal was not extortion or political.

NOTE: On the $1 / 29 / 72$ and 10/20/77 events both extortion and prisoner release were goals. Since in each case extortion appeared to be dominant motivation, these incidents were recorded as extortions.

Column 33 : The number of perpetrators involved in the hijacking

Column 35 : The number of perpetrators captured (including those captured later and including those killed in the act.)

Column $\quad 37$ : The number of perpetrators convicted. Includes those sent to juvenile correctional centers, those committed to a inental institution, and thuse who committed suicide while in prison prior to conviction.

Columns 41-45 : Prison sentence length (years) of convicted perpetrators (excludes those committed to juvenile centers or mental institutions). (If more than one perpetrator was involved the mean sentence length was computed. Iife sentences were given a value of 30 years.) ( $\Lambda$ In column 45 indicates perpetrator was sent to a juvenile center; $M$ indicates perpetrator was sent to a mental institution.)

NOTE: On $8 / 3 / 61$, there were two perpetrators, one was a juvenile. The adult's sentence was 25 years and is the value listed.

NOTE: The mean sentence length is the sum of sentence lengths divided by the number of sentences.

NOTE: A dot in any column indicates that information was either not applicable or not available. 